\title{
On solutions of a class of three-point fractional boundary value problems
}

\author{
Zhanbing Bai ${ }^{1}$, Yu Cheng ${ }^{1}$ and Sujing Sun ${ }^{1 *}$ (D)
}

"Correspondence: kdssi@163.com

${ }^{1}$ College of Mathematics and System Science, Shandong

University of Science and

Technology, Qingdao, P.R. China

\begin{abstract}
Existence results for the three-point fractional boundary value problem

$$
\begin{aligned}
& D^{\alpha} x(t)=f\left(t, x(t), D^{\alpha-1} x(t)\right), \quad 0<t<1, \\
& x(0)=A, \quad x(\eta)-x(1)=(\eta-1) B
\end{aligned}
$$

are presented, where $A, B \in \mathbb{R}, 0<\eta<1,1<\alpha \leq 2$. $D^{\alpha} x(t)$ is the conformable fractional derivative, and $f:[0,1] \times \mathbb{R}^{2} \rightarrow \mathbb{R}$ is continuous. The analysis is based on the nonlinear alternative of Leray-Schauder.
\end{abstract}

MSC: 34B18; 35J05; 34A08

Keywords: Boundary value problems; Conformable fractional derivative; Nonlinear alternative of Leray-Schauder

\section{Introduction}

In recent years, due to the wide application in many engineering and scientific disciplines as the mathematical modeling of systems and processes in the fields of physics, chemistry, aerodynamics, electrodynamics of a complex medium, polymer rheology, etc., the fractional differential equations have been widely studied. An extensive literature related to the existence of solutions of boundary value problems for fractional differential equations addressed by the use of various nonlinear functional analysis method. For example, fixed point theory $[5,7,9-11,19,21,25-28,32,33,39,50,52,56]$, the Mawhin continuation method $[3,6,54,57]$, the Green function method [5, 44, 45], the integral operator method $[4,8,13,14,17,22,30,31,35,36,38,49,51,53]$, the upper and lower solution method $[12,15,18,29]$, the numerical method $[40-43,46,55]$, and the technique of barrier strips $[4,16,20,24,34,37]$.

In [24], Kelevedjiev got the existence of the solution by using the technique of barrier strips. Then some researchers studied the solvability of vary boundary value problems under the barrier strip conditions. For example, in [32], by using a nonlinear alternative of Leray-Schauder, the existence results for the second-order three-point boundary value

(c) The Author(s) 2020. This article is licensed under a Creative Commons Attribution 4.0 International License, which permits use, sharing, adaptation, distribution and reproduction in any medium or format, as long as you give appropriate credit to the original author(s) and the source, provide a link to the Creative Commons licence, and indicate if changes were made. The images or other third party material in this article are included in the article's Creative Commons licence, unless indicated otherwise in a credit line to the material. If material is not included in the article's Creative Commons licence and your intended use is not permitted by statutory regulation or exceeds the permitted use, you will need to obtain permission directly from the copyright holder. To view a copy of this licence, visit http://creativecommons.org/licenses/by/4.0/. 
problem are obtained,

$$
\begin{aligned}
& x^{\prime \prime}(t)=f\left(t, x(t), x^{\prime}(t)\right), \quad 0<t<1, \\
& x(0)=A, \quad x(\eta)-x(1)=(\eta-1) B,
\end{aligned}
$$

where $\eta \in(0,1), f:[0,1] \times \mathbb{R}^{2} \rightarrow \mathbb{R}$ is continuous, and $A, B \in \mathbb{R}$. After that, the barrier strip technique was used to research the solvability of the difference problem [16] and the time scale problem [34]. Recently, in [20,37], the author obtained the existence of solutions for the fractional Dirichlet boundary value problem

$$
\begin{aligned}
& D^{\alpha} x(t)=f\left(t, x(t), D^{\alpha-1} x(t)\right), \quad 0<t<1, \\
& x(0)=A, \quad x(1)=B,
\end{aligned}
$$

under barrier strip conditions, where $1<\alpha \leq 2$ is a real number, $D^{\alpha} x(t)$ is the conformable fractional derivative, and $f:[0,1] \times \mathbb{R}^{2} \rightarrow \mathbb{R}$ is continuous.

To the best of the authors' knowledge, there were few papers discussing the solvability of the multi-point fractional boundary value problems with the technique of barrier strips. Our effort is to use the nonlinear alternative of Leray-Schauder to the unreached areas. In this paper, we consider the following fractional boundary value problem:

$$
\begin{aligned}
& D^{\alpha} x(t)=f\left(t, x(t), D^{\alpha-1} x(t)\right), \quad 0<t<1, \\
& x(0)=A, \quad x(\eta)-x(1)=(\eta-1) B,
\end{aligned}
$$

where $1<\alpha \leq 2$ is a real number, $D^{\alpha} x(t)$ is the conformable fractional derivative, $\eta \in(0,1)$, $f:[0,1] \times \mathbb{R}^{2} \rightarrow \mathbb{R}$ is continuous, and $A, B \in \mathbb{R}$. We note that if $x$ is a solution of (1.1), (1.2), then there exists $\xi \in(\eta, 1)$, such that $x^{\prime}(\xi)=B$. Accordingly, the boundary value problem

$$
\begin{aligned}
& D^{\alpha} x(t)=f\left(t, x(t), D^{\alpha-1} x(t)\right), \quad 0<t<1, \\
& x(0)=A, \quad x^{\prime}(1)=B, \quad 0<\eta<1,
\end{aligned}
$$

can be considered as a limiting case of the problem (1.1), (1.2) when $\eta=1$. Consequently, our result for problem (1.1), (1.2) gives an existence result for problem (1.3), (1.4).

It is true that the conformable derivative has some controversy. Some researchers think that the conformable derivative does not contribute "new mathematics". The conformable derivative for differentiable functions is equivalent to a simple change of variable $D^{\alpha}[f(x)]=x^{1-\alpha} f^{\prime}(x)$. It was noted that a criticism of the conformable derivative is that, although conformable at the limit $\alpha \rightarrow 1\left(\lim _{\alpha \rightarrow 1} D^{\alpha} f=f^{\prime}\right)$, it is not conformable at the other limit, $\alpha \rightarrow 0\left(\lim _{\alpha \rightarrow 0} D^{\alpha} f \neq f\right)$ because $x^{\alpha} / \alpha$ is undefined at $\alpha=0$.

However, some other researchers think that the conformable derivative and its generalizations can still be interesting and valuable, specially leading to some physical insight with use in the applied settings. We refer the reader to $[1,2,47,48]$ for details as regards the conformable fractional derivative.

The main results of the paper is based on the following nonlinear alternative of LeraySchauder. 
Theorem 1.1 ([32] (Nonlinear alternative)) Assume that $U$ is a relatively open subset of a convex set $K$ in a Banach space E. Let $N: \bar{U} \rightarrow K$ be a compact map and assume $p \in U$. Then either

(1) $N$ has a fixed point in $\bar{U}$; or

(2) there is $a u \in \partial U$ and $\lambda \in(0,1)$ such that $u=\lambda N u+(1-\lambda) p$.

The paper is organized as follows. In Sect. 2, the definitions of the conformable fractional order derivative and integral are given. In Sect. 3, by the use of the technique of nonlinear alternative of Leray-Schauder and barrier strips, the existence of the solution is obtained. In Sect. 4, some examples are presented to illustrate the main results.

\section{Conformable fractional order calculus}

Definition 2.1 ([23]) Suppose $\alpha \in(n, n+1], u:[0, \infty) \rightarrow R$, and $u$ is $n$ th-order differentiable for $t>0$. Then the $\alpha$ th-order fractional derivative of $u$ is defined as

$$
D^{\alpha} u(t)=\lim _{\varepsilon \rightarrow 0} \frac{u^{(n)}\left(t+e^{\varepsilon t^{n+1-\alpha}}\right)-u^{(n)}(t)}{\varepsilon}
$$

provided the limit of the right side exists.

If $u$ is $\alpha$ th-order differentiable on $(0, a), a>0$, and $\lim _{t \rightarrow 0^{+}} D^{\alpha} u(t)$ exists, then define $D^{\alpha} u(0)=\lim _{t \rightarrow 0^{+}} D^{\alpha} u(t)$.

Lemma 2.1 ([13]) Let $t>0, \alpha \in(n, n+1]$. Function $u(t)$ is $\alpha$ th-order differentiable if and only if $u$ is $(n+1)$ th-order differentiable, moreover,

$$
D^{\alpha} u(t)=t^{n+1-\alpha} u^{(n+1)}(t)
$$

Definition 2.2 ([23]) Let $\alpha \in(n, n+1]$, $\alpha$ th-order fractional integral is defined as

$$
J_{0+}^{\alpha} u(t)=I^{n+1}\left[t^{\alpha-n-1} u(t)\right]=\frac{1}{n !} \int_{0}^{t}(t-s)^{n} s^{\alpha-n-1} u(s) d s,
$$

where $I^{n+1}$ is the $(n+1)$ th-order integral.

Remark 2.1 With Lemma 2.1 and Definition 2.2, for $\alpha \in(n, n+1], i=0,1, \ldots, n$, there hold

$$
\begin{aligned}
D^{\alpha-i}\left[J_{0+}^{\alpha} u(t)\right] & =t^{n+1-\alpha} D^{n+1-i}\left[I^{n+1}\left(t^{\alpha-n-1} u(t)\right)\right] \\
& =t^{n+1-\alpha} I^{i}\left[t^{\alpha-n-1} u(t)\right] .
\end{aligned}
$$

Lemma $2.2([23])$ Let $a \geq 0, f:[a, b] \rightarrow \mathbb{R}$ satisfy,

(i) $f$ is continuous on $[a, b]$,

(ii) $f$ is $\alpha$ th-order differentiable on $(a, b)$.

Then there exists $c \in(a, b)$ such that

$$
D^{\alpha} f(c)=\frac{f(b)-f(a)}{\frac{1}{\alpha} b^{\alpha}-\frac{1}{\alpha} a^{\alpha}} .
$$


Given $\alpha \in(n, n+1]$. Define

$$
\begin{aligned}
C^{\alpha}[0,1]= & \left\{u \mid u(t)=J_{0^{+}}^{\alpha} x(t)+C_{n} t^{n}+\cdots+C_{1} t+C_{0},\right. \\
& \left.x(t) \in C[0,1], C_{i} \in \mathbb{R}, i=0,1, \ldots, n\right\} .
\end{aligned}
$$

By the linearity of integral operator $J_{0^{+}}^{\alpha}$, the space $C^{\alpha}[0,1]$ is a linear space. For $u \in C^{\alpha}[0,1]$, according to Remark 2.1 , there are $D^{\alpha-i} u(t) \in C[0,1], i=0,1, \ldots, n$. Let

$$
\|u\|_{\alpha}=\left\|D^{\alpha} u\right\|_{0}+\left\|D^{\alpha-1} u\right\|_{0}+\cdots+\left\|D^{\alpha-n} u\right\|_{0}+\|u\|_{0},
$$

where $\|u\|_{0}=\max _{t \in[0,1]}|u(t)|$. The following lemmas obtained in [13] are fundamental to our main results.

Lemma $2.3([13])$ The space $\left(C^{\alpha}[0,1],\|\cdot\|_{\alpha}\right)$ is a Banach space.

Lemma 2.4 ([13]) The set $F \subset C^{\alpha}[0,1]$ is sequentially compact if and only if $F$ is uniformly bounded and equicontinuous, i.e., for $\forall \varepsilon>0, \exists \delta>0$, s.t. for any $\left|t_{1}-t_{2}\right|<\delta, \forall u \in F$, $i=0,1, \ldots, N-1$, we have

$$
\left|D^{\alpha-i} u\left(t_{1}\right)-D^{\alpha-i} u\left(t_{2}\right)\right|<\varepsilon, \quad\left|u\left(t_{1}\right)-u\left(t_{2}\right)\right|<\varepsilon .
$$

Lemma 2.5 ([13]) Assume that $u \in C[0,1]$ with a fractional derivative of order $\alpha \in$ $(n, n+1]$ that belongs to $C(0,1) \cap L(0,1)$. Then

$$
I^{\alpha} D^{\alpha} u(t)=u(t)+c_{0}+c_{1} t+\cdots+c_{n} t^{n}
$$

for some $c_{k} \in \mathbb{R}, k=0,1, \ldots, n$.

Now, we present the Green function.

Lemma 2.6 Given $y \in C[0,1]$ and $1<\alpha \leq 2,1<\eta<2$, the unique solution of

$$
\begin{aligned}
& D^{\alpha} w(t)+y(t)=0, \quad 0<t<1, \\
& w(0)=0, \quad w(\eta)-w(1)=0
\end{aligned}
$$

is

$$
w(t)=\int_{0}^{1} G(t, s) y(s) d s,
$$

where

$$
G(t, s)= \begin{cases}s^{\alpha-1}, & 0 \leq s \leq t \leq 1, s \leq \eta \\ s^{\alpha-1}-t s^{\alpha-2}-\frac{s^{\alpha-2} t(1-s)}{\eta-1}, & 0 \leq \eta \leq s \leq t \leq 1 \\ t s^{\alpha-2}, & 0 \leq t \leq s \leq \eta \leq 1 \\ \frac{t s^{\alpha-2}(s-1)}{\eta-1}, & 0 \leq t \leq s \leq 1, \eta \leq s\end{cases}
$$


Proof Applying Lemma 2.5, we reduce Eq. (2.1) to an equivalent integral equation,

$$
\begin{aligned}
w(t) & =-I^{\alpha} y(t)+c_{0}+c_{1} t \\
& =-\int_{0}^{t}(t-s) s^{\alpha-2} y(s) d s+c_{0}+c_{1} t
\end{aligned}
$$

for some $c_{0}, c_{1} \in \mathbb{R}$. By the boundary condition (2.2), we have

$$
\begin{aligned}
& c_{0}=0, \\
& c_{1}=\int_{0}^{\eta} \frac{\eta-s}{\eta-1} s^{\alpha-2} y(s) d s-\int_{0}^{1} \frac{1-s}{\eta-1} s^{\alpha-2} y(s) d s .
\end{aligned}
$$

Therefore, the unique solution of problem (2.1), (2.2) is

$$
w(t)=-\int_{0}^{t}(t-s) s^{\alpha-2} y(s) d s+\int_{0}^{\eta} \frac{t(\eta-s)}{\eta-1} s^{\alpha-2} y(s) d s-\int_{0}^{1} \frac{t(1-s)}{\eta-1} s^{\alpha-2} y(s) d s .
$$

For $0 \leq \eta \leq t \leq 1$, one has

$$
\begin{aligned}
w(t)= & -\left(\int_{0}^{\eta}+\int_{\eta}^{t}\right)(t-s) s^{\alpha-2} y(s) d s+\int_{0}^{\eta} \frac{t(\eta-s)}{\eta-1} s^{\alpha-2} y(s) d s \\
& -\left(\int_{0}^{\eta}+\int_{\eta}^{t}+\int_{t}^{1}\right) \frac{t(1-s)}{\eta-1} s^{\alpha-2} y(s) d s \\
= & \int_{0}^{\eta} s^{\alpha-1} y(s) d s+\int_{\eta}^{t}\left(s^{\alpha-1}-t s^{\alpha-2}-\frac{s^{\alpha-2} t(1-s)}{\eta-1}\right) y(s) d s \\
& +\int_{t}^{1} \frac{t s^{\alpha-2}(s-1)}{\eta-1} y(s) d s \\
= & \int_{0}^{1} G(t, s) y(s) d s .
\end{aligned}
$$

For $0 \leq t \leq \eta \leq 1$, one has

$$
\begin{aligned}
w(t)= & -\int_{0}^{t}(t-s) s^{\alpha-2} y(s) d s+\left(\int_{0}^{t}+\int_{t}^{\eta}\right) \frac{t(\eta-s)}{\eta-1} s^{\alpha-2} y(s) d s \\
& -\left(\int_{0}^{t}+\int_{t}^{\eta}+\int_{\eta}^{1}\right) \frac{t(1-s)}{\eta-1} s^{\alpha-2} y(s) d s \\
= & \int_{0}^{t} s^{\alpha-1} y(s) d s+\int_{t}^{\eta} t s^{\alpha-2} y(s) d s+\int_{\eta}^{1} \frac{t s^{\alpha-2}(s-1)}{\eta-1} y(s) d s \\
= & \int_{0}^{1} G(t, s) y(s) d s .
\end{aligned}
$$

The proof is complete.

\section{Existence results}

Theorem 3.1 Let $f:[0,1] \times \mathbb{R}^{2} \rightarrow \mathbb{R}$ be continuous, $A \in \mathbb{R}, B \geq 0$. Suppose there are constants $L_{2} \leq L_{1}$ such that $L_{2}-B<0 \leq L_{1}$ and 
(1) $f(t, x, p) \geq 0$, for $(t, x, p) \in[0,1] \times\left[A+\frac{L_{2}-B}{\alpha-1}, A+B+\frac{L_{1}}{\alpha-1}\right] \times\left[L_{1}, L_{1}+B\right]$;

(2) $f(t, x, p) \leq 0$, for $(t, x, p) \in[0,1] \times\left[A+\frac{L_{2}-B}{\alpha-1}, A+B+\frac{L_{1}}{\alpha-1}\right] \times\left[L_{2}-B, L_{2}\right]$;

(3) $\frac{L_{2}-B}{1-\eta} \leq f(t, x, p) \leq \frac{L_{1}}{1-\eta}$, for $(t, x, p) \in[0,1] \times\left[A+\frac{L_{2}-B}{\alpha-1}, A+B+\frac{L_{1}}{\alpha-1}\right] \times\left[L_{2}-B, L_{1}+B\right]$.

Then the problem (1.1), (1.2) has at least one solution $x$ such that

$$
L_{2}-B \leq\left(D^{\alpha-1} x\right)(t) \leq L_{1}+B, \quad A+\frac{L_{2}-B}{\alpha-1} \leq x(t) \leq A+B+\frac{L_{1}}{\alpha-1} .
$$

Proof By the use of the Tietze-Uryshon lemma there exists a continuous function $g$ : $\mathbb{R}^{2} \rightarrow[-1,1]$ such that

$$
\begin{aligned}
& g(x, p)=1, \quad \text { on }\left[A+\frac{L_{2}-B}{\alpha-1}, A+B+\frac{L_{1}}{\alpha-1}\right] \times\left[L_{1}, L_{1}+B\right] ; \\
& g(x, p)=-1, \quad \text { on }\left[A+\frac{L_{2}-B}{\alpha-1}, A+B+\frac{L_{1}}{\alpha-1}\right] \times\left[L_{2}-B, L_{2}\right] .
\end{aligned}
$$

For each integer $n \geq 1$, set

$$
f_{n}(t, x, p)=f(t, x, p)+\frac{1}{n} g(x, p) .
$$

Then

$$
f_{n}(t, x, p)>0
$$

for $(t, x, p) \in[0,1] \times\left[A+\frac{L_{2}-B}{\alpha-1}, A+B+\frac{L_{1}}{\alpha-1}\right] \times\left[L_{1}, L_{1}+B\right]$

$$
f_{n}(t, x, p)<0,
$$

for $(t, x, p) \in[0,1] \times\left[A+\frac{L_{2}-B}{\alpha-1}, A+B+\frac{L_{1}}{\alpha-1}\right] \times\left[L_{2}-B, L_{2}\right]$.

Consider the boundary value problems

$$
\begin{aligned}
& D^{\alpha} x(t)=f_{n}\left(t, x(t), D^{\alpha-1} x(t)\right), \quad 0<t<1, \\
& x(0)=A, \quad x(\eta)-x(1)=(\eta-1) B .
\end{aligned}
$$

Making the change of variables $w(t)=x(t)-\mu(t)$, where $\mu(t)=B t+A$. It is clear that $x(t)$ is a solution of (3.3), (3.4) if and only if $w(t)$ satisfies

$$
\begin{aligned}
& D^{\alpha} w(t)=f_{n}\left(t, w(t)+\mu(t), D^{\alpha-1} w(t)+D^{\alpha-1} \mu(t)\right), \\
& w(0)=0, \quad w(\eta)-w(1)=0 .
\end{aligned}
$$

Define $T_{n}: C^{\alpha}[0,1] \rightarrow C^{\alpha}[0,1]$ as

$$
\left(T_{n} w\right)(t)=\int_{0}^{1} G(t, s) f_{n}\left(s, w(s)+\mu(s), D^{\alpha-1} w(s)+D^{\alpha-1} \mu(s)\right) d s
$$

where $G(t, s)$ is the Green function defined in Eq. (2.3). The standard arguments show that $T_{n}: C^{\alpha}[0,1] \rightarrow C^{\alpha}[0,1]$ is completely continuous. Furthermore, the solvability of the problem (3.3), (3.4) is changed as the existence of the fixed point of the operator $T_{n}$. 
Now, we are in the position to show that the operator $T_{n}$ has a fixed point $w_{n}$ that satisfies

$$
\begin{aligned}
& L_{2}-B \leq\left(D^{\alpha-1} w_{n}\right)(t) \leq L_{1}, \quad t \in[0,1], \\
& \frac{L_{2}-B}{\alpha-1} \leq w_{n}(t) \leq \frac{L_{1}}{\alpha-1}, \quad t \in[0,1],
\end{aligned}
$$

for all $n \in N$. Once this is achieved, then, by combining (3.7), (3.8), (3.9) and Lemmas $2.3,2.4$, the sequence $\left\{w_{n}\right\}$ has a subsequence which converges in $C^{\alpha}$-topology to $w_{0}$, and then $x(t):=w_{0}(t)+\mu(t)$ is a solution of (1.1), (1.2) such that

$$
\begin{aligned}
& L_{2}-B \leq\left(D^{\alpha-1} x\right)(t) \leq L_{1}+B, \\
& A+\frac{L_{2}-B}{\alpha-1} \leq x(t) \leq A+B+\frac{L_{1}}{\alpha-1} .
\end{aligned}
$$

Define $U$ as the open and bounded neighborhood of $0 \in C^{\alpha-1}[0,1]$ such that

$$
U=\left\{v \in C^{\alpha-1}[0,1] \mid \frac{L_{2}-B}{\alpha-1}<v(t)<\frac{L_{1}}{\alpha-1}, L_{2}-B<D^{\alpha-1} v(t)<L_{1}\right\} .
$$

To prove that $T_{n}$ has a solution $w_{n} \in \bar{U}$ such that (3.8) holds, it suffices to verify, in view of Theorem 1.1, that if $w \in \bar{U}$ satisfies Eq. (3.6) such that

$$
w(t)=\lambda\left(T_{n} w\right)(t)
$$

for some $\lambda \in(0,1)$, then $w \in U$, i.e., for $0<t<1$,

$$
\frac{L_{2}-B}{\alpha-1}<w(t)<\frac{L_{1}}{\alpha-1}, \quad \text { and } \quad L_{2}-B<\left(D^{\alpha-1} w\right)(t)<L_{1} .
$$

Now let $w \in \bar{U}$ satisfies Eq. (3.6) for some $\lambda \in(0,1)$. Since $L_{2}-B \leq\left(D^{\alpha-1} w_{n}\right)(t) \leq L_{1}$, by Lemma 2.2, there exists $c \in(0, t) \subset(0,1)$ such that

$$
w(t)-w(0)=\left(D^{\alpha-1} w\right)(c) \cdot \frac{t^{\alpha-1}}{\alpha-1}
$$

and

$$
\left(L_{2}-B\right) \cdot \frac{t^{\alpha-1}}{\alpha-1} \leq w(t) \leq L_{1} \cdot \frac{t^{\alpha-1}}{\alpha-1} .
$$

Let $x(t)=w(t)+\mu(t)$, then $x(t)$ satisfies

$$
L_{2}-B \leq\left(D^{\alpha-1} x\right)(t) \leq L_{1}+B
$$

and

$$
\left(L_{2}-B\right) \cdot \frac{t^{\alpha-1}}{\alpha-1}+B t+A \leq x(t) \leq L_{1} \cdot \frac{t^{\alpha-1}}{\alpha-1}+B t+A .
$$

In particular

$$
A+\frac{L_{2}-B}{\alpha-1} \leq x(t) \leq A+B+\frac{L_{1}}{\alpha-1} .
$$


Suppose that $D^{\alpha-1} w\left(t_{0}\right)=L_{1}$ for some $t_{0} \in[0,1]$. We claim that $t_{0}<1$. In fact, due to $w \in C^{\alpha-1}[0,1]$ and $w(\eta)=w(1)$, by the use of the Lemma 2.2 , there exists $\xi \in(\eta, 1)$ such that $D^{\alpha-1}(\xi)=0$. Taking into account the condition (3), integrating Eq. (3.5) from $\xi$ to 1 yields

$$
\begin{aligned}
D^{\alpha-1} w(1) & =D^{\alpha-1} w(\xi)+\int_{\xi}^{1}\left(D^{\alpha} w\right)(s) d s \\
& =\int_{\xi}^{1} f_{n}\left(s, w(s)+\mu(s), D^{\alpha-1} w(s)+D^{\alpha-1} \mu(s)\right) d s \\
& \leq(1-\xi) \frac{L_{1}}{1-\eta}<L_{1} .
\end{aligned}
$$

Hence $D^{\alpha} w\left(t_{0}\right) \leq 0$ because $D^{\alpha-1} w(t)$ attains its maximum at $t_{0}$.

On the other hand, by (3.13) we get

$$
\begin{aligned}
D^{\alpha} w\left(t_{0}\right) & =\lambda f_{n}\left(t_{0}, w\left(t_{0}\right)+\mu\left(t_{0}\right), D^{\alpha-1} w\left(t_{0}\right)+D^{\alpha-1} \mu\left(t_{0}\right)\right) \\
& =\lambda f_{n}\left(t_{0}, w\left(t_{0}\right)+A+B t_{0}, L_{1}+t_{0}^{2-\alpha} B\right)>0 .
\end{aligned}
$$

This contradiction proves that $D^{\alpha-1} w\left(t_{0}\right)<L_{1}$. Analogously, we have $D^{\alpha-1} w\left(t_{0}\right)>L_{2}-B$. Thus we get

$$
L_{2}-B<D^{\alpha-1} w(t)<L_{1}
$$

Inequality (3.14) together with the relation $w(t)=w(0)+D^{\alpha-1} w(d) \cdot \frac{t^{\alpha-1}}{\alpha-1}$ implies that

$$
\frac{L_{2}-B}{\alpha-1}<w(t)<\frac{L_{1}}{\alpha-1}
$$

This completes the proof.

Analogously, we can obtain the following result.

Theorem 3.2 Let $f:[0,1] \times \mathbb{R}^{2} \rightarrow \mathbb{R}$ be continuous, $A \in \mathbb{R}, B<0$. Suppose there are constants $L_{1}, L_{2}$ such that $L_{2} \leq L_{1}+2 B, L_{2} \leq B<0 \leq L_{1}$ and

(1) $f(t, x, p) \geq 0$, for $(t, x, p) \in[0,1] \times\left[A+B+\frac{L_{2}-B}{\alpha-1}, A+\frac{L_{1}}{\alpha-1}\right] \times\left[L_{1}+B, L_{1}\right]$;

(2) $f(t, x, p) \leq 0$, for $(t, x, p) \in[0,1] \times\left[A+\frac{L_{2}-B}{\alpha-1}, A+B+\frac{L_{1}}{\alpha-1}\right] \times\left[L_{2}, L_{2}-B\right]$;

(3) $\frac{L_{2}-B}{1-\eta} \leq f(t, x, p) \leq \frac{L_{1}}{1-\eta}$, for $(t, x, p) \in[0,1] \times\left[A+B+\frac{L_{2}-B}{\alpha-1}, A+\frac{L_{1}}{\alpha-1}\right] \times\left[L_{2}, L_{1}\right]$.

Then the problem (1.1), (1.2) has at least one solution $x$ such that

$$
L_{2} \leq\left(D^{\alpha-1} x\right)(t) \leq L_{1}, \quad A+B+\frac{L_{2}-B}{\alpha-1} \leq x(t) \leq A+\frac{L_{1}}{\alpha-1} .
$$

Accordingly, we get the following corollaries as consequences of Theorems 3.1 and 3.2 for the boundary value problem (1.3), (1.4).

Corollary 3.1 Let $f:[0,1] \times \mathbb{R}^{2} \rightarrow \mathbb{R}$ be continuous, $A \in \mathbb{R}, B \geq 0$. Suppose there are constants $L_{2} \leq L_{1}$ such that $L_{2}-B \leq 0 \leq L_{1}$ and

(1) $f(t, x, p) \geq 0$, for $(t, x, p) \in[0,1] \times\left[A+\frac{L_{2}-B}{\alpha-1}, A+B+\frac{L_{1}}{\alpha-1}\right] \times\left[L_{1}, L_{1}+B\right]$;

(2) $f(t, x, p) \leq 0$, for $(t, x, p) \in[0,1] \times\left[A+\frac{L_{2}-B}{\alpha-1}, A+B+\frac{L_{1}}{\alpha-1}\right] \times\left[L_{2}-B, L_{2}\right]$. 
Then the problem (1.3), (1.4) has at least one solution $x$ such that

$$
L_{2}-B \leq\left(D^{\alpha-1} x\right)(t) \leq L_{1}+B, \quad A+\frac{L_{2}-B}{\alpha-1} \leq x(t) \leq A+B+\frac{L_{1}}{\alpha-1}
$$

Proof It suffices to note in the case $\eta=1$ that the boundary condition $x^{\prime}(1)=B$ implies that $L_{2}-B<w^{\prime}(1)=0<L_{1}$ which is what is required in applying the condition (3) to show $t_{0}<1$ in the proof of Theorem 3.1.

Corollary 3.2 Let $f:[0,1] \times \mathbb{R}^{2} \rightarrow \mathbb{R}$ be continuous, $A \in \mathbb{R}, B<0$. Suppose there are constants $L_{1}, L_{2}$ such that $L_{2} \leq L_{1}+2 B, L_{2} \leq B<0 \leq L_{1}$ and

(1) $f(t, x, p) \geq 0$, for $(t, x, p) \in[0,1] \times\left[A+B+\frac{L_{2}-B}{\alpha-1}, A+\frac{L_{1}}{\alpha-1}\right] \times\left[L_{1}+B, L_{1}\right]$;

(2) $f(t, x, p) \leq 0$, for $(t, x, p) \in[0,1] \times\left[A+\frac{L_{2}-B}{\alpha-1}, A+B+\frac{L_{1}}{\alpha-1}\right] \times\left[L_{2}, L_{2}-B\right]$.

Then the problem (1.3), (1.4) has at least one solution $x$ such that

$$
L_{2} \leq\left(D^{\alpha-1} x\right)(t) \leq L_{1}, \quad A+B+\frac{L_{2}-B}{\alpha-1} \leq x(t) \leq A+\frac{L_{1}}{\alpha-1}
$$

\section{Some examples}

Example 4.1 Let $\alpha=\frac{3}{2}, A=0, B=\frac{1}{2}, \eta=\frac{1}{5}$, consider the following problem:

$$
\begin{aligned}
& D^{\alpha} x(t)=f\left(t, x(t), D^{\alpha-1} x(t)\right), \quad 0<t<1, \\
& x(0)=0, \quad x\left(\frac{1}{5}\right)-x(1)=-\frac{2}{5},
\end{aligned}
$$

where $f(t, x, p)=\frac{t^{2}}{8} \sin \left(x^{2}+t^{2}\right)+p^{3}$.

Choose $L_{1}=1$ and $L_{2}=-\frac{1}{2}$, then $L_{1}+B=\frac{3}{2}, L_{2}-B=-1$ and

$$
\begin{aligned}
& {\left[A+\frac{L_{2}-B}{\alpha-1}, A+B+\frac{L_{1}}{\alpha-1}\right]=\left[-2, \frac{5}{2}\right],} \\
& {\left[\frac{L_{2}-B}{1-\eta}, \frac{L_{1}}{1-\eta}\right]=\left[-\frac{5}{4}, \frac{5}{4}\right] .}
\end{aligned}
$$

After a simple computation, we have

(1) $f(t, x, p) \geq 1 \geq 0$, for $(t, x, p) \in[0,1] \times\left[-2, \frac{5}{2}\right] \times\left[1, \frac{3}{2}\right]$,

(2) $f(t, x, p) \leq 0$, for $(t, x, p) \in[0,1] \times\left[-2, \frac{5}{2}\right] \times\left[-1,-\frac{1}{2}\right]$,

(3) $-\frac{5}{4}<-1 \leq f(t, x, p) \leq \frac{5}{4}$, for $(t, x, p) \in[0,1] \times\left[-2, \frac{5}{2}\right] \times\left[-1, \frac{3}{2}\right]$.

That is to say that all the conditions of Theorem 3.1 are satisfied, so the problem (4.1),

(4.2) has at least one solution $x$ such that

$$
-1 \leq D^{\frac{1}{2}} x(t) \leq \frac{3}{2}, \quad-2 \leq x(t) \leq \frac{5}{2}, \quad \text { for } 0 \leq t \leq 1
$$

Example 4.2 Consider the following problem:

$$
\begin{aligned}
& D^{\alpha} x(t)=f\left(t, x(t), D^{\alpha-1} x(t)\right), \quad 0<t<1, \\
& x(0)=0, \quad x^{\prime}(1)=-1,
\end{aligned}
$$

where $\alpha=\frac{3}{2}, A=0, B=-1, f(t, x, p)=t^{2} \sin \left(x^{2}+t^{2}\right)+p^{3}$. 
Choose $L_{1}=2$ and $L_{2}=-2$, then $L_{1}+B=1, L_{2}-B=-1, L_{2} \leq 0=L_{1}+2 B, L_{2} \leq B<0 \leq L_{1}$ and

$$
\begin{aligned}
& {\left[A+B+\frac{L_{2}-B}{\alpha-1}, A+\frac{L_{1}}{\alpha-1}\right]=[-3,4] ;} \\
& {\left[A+\frac{L_{2}-B}{\alpha-1}, A+B+\frac{L_{1}}{\alpha-1}\right]=[-2,-3] .}
\end{aligned}
$$

After a simple computation, we have

(1) $f(t, x, p) \geq 0$, for $(t, x, p) \in[0,1] \times[-3,4] \times[1,2]$,

(2) $f(t, x, p) \leq 0$, for $(t, x, p) \in[0,1] \times[-2,-3] \times[-2,-1]$.

All the conditions of Corollary 3.2 are satisfied, so the problem (4.3), (4.4) has at least one solution $x$ such that

$$
-2 \leq D^{\frac{1}{2}} x(t) \leq 2, \quad-3 \leq x(t) \leq 4, \quad \text { for } 0 \leq t \leq 1 .
$$

\section{Acknowledgements}

Not applicable.

\section{Funding}

This work is supported by NSFC (11571207) and the Taishan Scholar project.

\section{Availability of data and materials}

Data sharing not applicable to this article as no data sets were generated or analysed during the current study.

\section{Competing interests}

The authors declare that they have no competing interests.

\section{Authors' contributions}

All authors contributed equally to the writing of this paper. All authors read and approved the final manuscript.

\section{Authors' information}

Zhanbing Bai, professor, his main research field is fractional differential equation boundary value problem. Yu Cheng, doctoral candidate, her research field is the fractional calculus with applications. Sujing Sun, doctoral candidate, her research field is the application of nonlinear functional analysis on differential equations.

\section{Publisher's Note}

Springer Nature remains neutral with regard to jurisdictional claims in published maps and institutional affiliations.

Received: 21 July 2019 Accepted: 29 December 2019 Published online: 10 January 2020

\section{References}

1. Abdelhakim, A., Machado, J.: A critical analysis of the conformable derivative. Nonlinear Dyn. 95, 3063-3073 (2019). https://doi.org/10.1007/s11071-018-04741-5

2. Anderson, D., Camrud, E., Ulness, D.: On the nature of the conformable derivative and its applications to physics. J. Fract. Calc. Appl. 10(2), 92-135 (2019)

3. Bai, Z:: Solvability for a class of fractional $m$-point boundary value problem at resonance. Comput. Math. Appl. 62, 1292-1302 (2011)

4. Bai, Z., Chen, Y., Lian, H., Sun, S.: On the existence of blow up solutions for a class of fractional differential equations. Fract. Calc. Appl. Anal. 17(4), 1175-1187 (2014)

5. Bai, Z., Du, Z., Zhang, S.: Iterative method for a class of fourth-order $p$-Laplacian beam equation. J. Appl. Anal. Comput. 9(4), 1443-1453 (2019)

6. Bai, Z., Zhang, Y.: Solvability of fractional three-point boundary value problems with nonlinear growth. Appl. Math. Comput. 218(5), 1719-1725 (2011)

7. Boucherif, A.: Nonlinear multipoint boundary value problems. Nonlinear Anal. 10, 957-964 (1986)

8. Cabada, A., Wang, G.: Positive solutions of nonlinear fractional differential equations with integral boundary value conditions. Abstr. Appl. Anal. 2012, Article ID 403 (2012)

9. Cao, J., Song, G., Wang, J., Shi, Q., Sun, S.: Blow-up and global solutions for a class of time fractional nonlinear reaction-diffusion equation with weakly spatial source. Appl. Math. Lett. 91, 201-206 (2019)

10. Cui, Y., Ma, W., Wang, X., Su, X.: Uniqueness theorem of differential system with coupled integral boundary conditions. Electron. J. Qual. Theory Differ. Equ. 2018, Article ID 9 (2018)

11. Cui, Y., Sun, J.: Positive solutions for second-order three-point boundary value problems in Banach spaces. Acta Math Sin. 4, 743-751 (2011) 
12. Dong, H., Guo, B., Yin, B.: Generalized fractional supertrace identity for Hamiltonian structure of NLS-MKdV hierarchy with self-consistent sources. Anal. Math. Phys. 6, 199-209 (2016)

13. Dong, X., Bai, Z., Zhang, S.: Positive solutions to boundary value problems of $p$-Laplacian with fractional derivative. Bound. Value Probl. 2017, Article ID 5 (2017)

14. Feng, M., Li, P., Sun, S.: Symmetric positive solutions for fourth-order $n$-dimensional $m$-Laplace systems. Bound. Value Probl. 2018, Article ID 63 (2018). https://doi.org/10.1186/s13661-018-0981-3

15. Fu, C., Lu, C., Yang, H.: Time-space fractional $(2+1)$ dimensional nonlinear Schrodinger equation for envelope gravity waves in baroclinic atmosphere and conservation laws as well as exact solutions. Adv. Differ. Equ. 2018, Article ID 56 (2018)

16. Gao, C.: Existence of solutions to $p$-Laplacian difference equations under barrier strips conditions. Electron. J. Differ. Equ. 2007, Article ID 59 (2007)

17. Granas, A., Guenther, R.: Application of topological transversality to differential equations I. Pac. J. Math. 89, 53-67 (1980)

18. Guo, M., Fu, C., Zhang, Y., Liu, J., Yang, H.: Study of ion-acoustic solitary waves in a magnetized plasma using the three-dimensional time-space fractional Schamel-KdV equation. Complexity 2018, Article ID 6852548 (2018). https://doi.org/10.1155/2018/6852548

19. Guo, X., Zhang, G., Li, H.: Fixed point theorems for Meir-Keeler condensing nonself-mappings with an application. J. Fixed Point Theory Appl. 2018, Article ID 33 (2018)

20. He, L., Dong, X., Bai, Z., Chen, B.: Solvability of some two-point fractional boundary value problems under barrier strip conditions. J. Funct. Spaces 2017, Article ID 1465623 (2017)

21. Jia, M., Wang, P.: Multiple positive solutions for integro-differential equations with integral boundary conditions and sign changing nonlinearities. Electron. J. Differ. Equ. 2012, Article ID 31 (2012)

22. Jiang, C., Zhang, F., Li, T.: Synchronization and anti-synchronization of N-coupled fractional-order complex systems with ring connection. Math. Methods Appl. Sci. 41, 2625-2638 (2018)

23. Katugampola, U:: A new fractional derivative with classical properties (2014). arXiv:1410.6535

24. Kelevedjiev, P.: Existence of solutions for two point boundary value problems. Nonlinear Anal. TMA 22, 217-224 (1994)

25. Li, H.: Existence of nontrivial solutions for superlinear three-point boundary value problems. Acta Math. Appl. Sin Engl. Ser. 33, 1043-1052 (2017)

26. Li, H., Sun, F.: Existence of solutions for integral boundary value problems of second-order ordinary differential equations. Bound. Value Probl. 2012, Article ID 147 (2012)

27. Li, H., Sun, J.: Positive solutions of superlinear semipositone nonlinear boundary value problems. Comput. Math. Appl. 61, 2806-2815 (2011)

28. Li, Z., Bai, Z.: Existence of solutions for some two-point fractional boundary value problems under barrier strip conditions. Bound. Value Probl. 2019, Article ID 192 (2019). https://doi.org/10.1186/s13661-019-01307-1.

29. Liu, X., Jia, M.: The method of lower and upper solutions for the general boundary value problems of fractional differential equations with p-Laplacian. Adv. Differ. Equ. 2018, Article ID 28 (2018)

30. Liu, X., Jia, M.: Solvability and numerical simulations for BVPs of fractional coupled systems involving left and right fractional derivatives. Appl. Math. Comput. 353, 230-242 (2019)

31. Lu, C., Fu, C., Yang, H.: Time-fractional generalized Boussinesq equation for Rossby solitary waves with dissipation effect in stratified fluid and conservation laws as well as exact solutions. Appl. Math. Comput. 327, 104-116 (2018)

32. Ma, R.: Existence theorems for a second order three-point boundary value problem. J. Math. Anal. Appl. 212, 430-442 (1997)

33. Ma, R.: Positive solutions of nonlinear three-point boundary value problem. Electron. J. Differ. Equ. 1998, Article ID 34 (1998)

34. Ma, R., Luo, H.: Existence of solutions for a two-point boundary value problem on time scales. Appl. Math. Comput. $150,139-147(2004)$

35. Sheng, K., Zhang, W., Bai, Z.: Positive solutions to fractional boundary value problems with $p$-Laplacian on time scales Bound. Value Probl. 2018, Article ID 70 (2018). https://doi.org/10.1186/s13661-018-0990-2

36. Song, Q., Bai, Z.: Positive solutions of fractional differential equations involving the Riemann-Stieltjes integral boundary condition. Adv. Differ. Equ. 2018, Article ID 183 (2018). https://doi.org/10.1186/s13662-018-1633-8

37. Song, Q., Dong, X., Bai, Z., Chen, B.: Existence for fractional Dirichlet boundary value problem under barrier strip conditions. J. Nonlinear Sci. Appl. 10, 3592-3598 (2017)

38. Tian, Y., Wei, Y., Sun, S.: Multiplicity for fractional differential equations with p-Laplacian. Bound. Value Probl. 2018, Article ID 127 (2018). https://doi.org/10.1186/s13661-018-1049-0

39. Wang, G., Ren, X., Bai, Z., Hou, W.: Radial symmetry of standing waves for nonlinear fractional Hardy-Schrödinger equation. Appl. Math. Lett. 96, 131-137 (2019)

40. Wang, Z.: A numerical method for delayed fractional-order differential equations. J. Appl. Math. 2013, Article ID 256071 (2013)

41. Wang, Z., Huang, X., Shi, G.: Analysis of nonlinear dynamics and chaos in a fractional order financial system with time delay. Comput. Math. Appl. 62, 1531-1539 (2011)

42. Wang, Z., Wang, X., Li, Y., Huang, X.: Stability and Hopf bifurcation of fractional-order complex valued single neuron model with time delay. Int. J. Bifurc. Chaos 27, Article ID 1750209 (2017)

43. Wang, Z., Xie, Y., Lu, J., Li, Y.: Stability and bifurcation of a delayed generalized fractional-order prey-predator model with interspecific competition. Appl. Math. Comput. 347, 360-369 (2019)

44. Wei, Y., Bai, Z.: Solvability of some fractional boundary value problems with a convection term. Discrete Dyn. Nat. Soc. 2019, Article ID 1230502 (2019). https://doi.org/10.1155/2019/1230502

45. Wei, Y., Bai, Z., Sun, S.: On positive solutions for some second-order three-point boundary value problems with convection term. J. Inequal. Appl. 2019, Article ID 72 (2019). https://doi.org/10.1186/s13660-019-2029-3

46. Wei, Y., Song, Q., Bai, Z.: Existence and iterative method for some fourth order nonlinear boundary value problems. Appl. Math. Lett. 87, 101-107 (2019)

47. Yang, S., Wang, L., Zhang, S.: Conformable derivative: application to non-Darcian flow in low-permeability porous media. Appl. Math. Lett. 79, 105-110 (2018) 
48. Zafar, A.: Rational exponential solutions of conformable space-time fractional equal-width equations. Nonlinear Eng. 8, 350-355 (2019)

49. Zhai, C., Wang, W., Li, H.: A uniqueness method to a new Hadamard fractional differential system with four-point boundary conditions. J. Inequal. Appl. 2018, Article ID 207 (2018)

50. Zhang, J., Zhang, G., Li, H.: Positive solutions of second-order problem with dependence on derivative in nonlinearity under Stieltjes integral boundary condition. Electron. J. Qual. Theory Differ. Equ. 2018, Article ID 4 (2018). https://doi.org/10.14232/ejqtde.2018.1.4

51. Zhang, T., Meng, X., Song, Y., Zhang, T.: A stage-structured predator-prey SI model with disease in the prey and impulsive effects. Math. Model. Anal. 18, 505-528 (2013)

52. Zhang, W., Bai, Z., Sun, S.: Extremal solutions for some periodic fractional differential equations. Adv. Differ. Equ. 2016, Article ID 179 (2016)

53. Zhang, X., Wu, Y., Cui, Y.: Existence and nonexistence of blow-up solutions for a Schrödinger equation involving a nonlinear operator. Appl. Math. Lett. 82, 85-91 (2018)

54. Zhang, Y.: Existence results for a coupled system of nonlinear fractional multi-point boundary value problems at resonance. J. Inequal. Appl. 2018, Article ID 198 (2018). https://doi.org/10.1186/s13660-018-1792-X

55. Zhong, Q., Zhang, X., Lu, X. Fu, Z: Uniqueness of successive positive solution for nonlocal singular higher-order fractional differential equations involving arbitrary derivatives. J. Funct. Spaces 2018, Article ID 6207682 (2018)

56. Zou, Y., Cui, Y.: Existence results for a functional boundary value problem of fractional differential equations. Adv. Differ. Equ. 2013, Article ID 233 (2013)

57. Zou, Y., Liu, L., Cui, Y.: The existence of solutions for four-point coupled boundary value problems of fractional differential equations at resonance. Abstr. Appl. Anal. 2014, Article ID 314083 (2014)

\section{Submit your manuscript to a SpringerOpen ${ }^{\circ}$ journal and benefit from:}

- Convenient online submission

- Rigorous peer review

- Open access: articles freely available online

- High visibility within the field

- Retaining the copyright to your article

Submit your next manuscript at $\boldsymbol{\triangleright}$ springeropen.com 